\title{
Comparison of Return Options for Reusable First Stages
}

\author{
Leonid Bussler, Martin Sippel \\ Space Launcher Systems Analysis (SART), DLR, Bremen, Germany \\ Leonid.Bussler@dlr.de Tel. +49-421-244201175, Fax. +49-421-244201150 \\ Martin.Sippel@dlr.de Tel. +49-421-244201145, Fax.+49-421-244201150
}

\begin{abstract}
DLR's Space Launcher Systems Analysis division analyzes generic Reusable Launch Vehicles for missions to Geostationary Transfer Orbit. The launcher configurations consist of a reusable first stage and two expendable upper stages. For the reusable first stage different separation Mach numbers are considered. The return options considered are stage fly-back and stage in-air capturing. Based on mass estimation, analysis of ascent and descent aerodynamics as well as ascent and reentry trajectory optimization first results for the return options stage fly-back and in-air capturing are presented.
\end{abstract}

\section{Introduction}

Launch vehicle reusability has the potential to lower the cost of access to space and significantly increase the efficiency of space transportation. Reusable first stages in combination with expendable upper stages are a first step towards fully reusable launch vehicles. The goal of the present study is to analyze and compare reusable first stage concepts and their respective return options in terms of both feasibility and payload performance. While this paper deals with stage fly-back and in-air capturing the present study is only a first step towards a critical comparison of existing return options for reusable first stages.

The defined target orbit is the Geostationary Transfer Orbit (GTO) with a payload target of 7.5 metric tons. The propellant combination is LH2/LOX for both upper and first stages. In order to recover the first stage two different methods have been considered: stage fly-back and in-air capturing. In both cases the reusable first stage is winged and either is flying back to the launch site using air-breathing propulsion or is towed back to the launch site by a carrier aircraft after inair capturing. Three different separation Mach numbers, namely 6, 9 and 12, are considered. Fly Back Boosters have been analyzed in DLR's Space Launcher Systems Analysis division for several years with one of the more widely known concepts being the Ariane 5 Liquid Fly Back Booster (LFBB), see [1], [2]. Stage in-air capturing has been analyzed in DLR leading to a patented method for stage recovery ([3], [4]) and its investigation is continued at present.

For all concepts an iterative approach is followed in the course of which the established models are refined towards a converged preliminary design. Mass estimation for the second and third stages is done using propellant load dependent structural index functions. For the reusable first stage a more detailed mass model based on empirical mass estimation methods is defined. The defined mass, aerodynamic and propulsion models provide inputs for ascent and descent trajectory simulation and optimization.

The defined configurations are compared in terms of payload performance, dimensions and mass, mechanical and thermal loads as well as required fly-back propellant in case of stage fly-back. 


\section{General Approach}

The general approach followed in this study is to start with a first basic vehicle definition consisting of an aerodynamic model for the ascent configuration, stage mass models based on structural index functions and propulsion system characteristics. This allows a first ascent trajectory simulation and optimization delivering first results for the payload mass injected into the target orbit.

Once the target payload mass is achieved with a certain staging a more detailed mass model is defined for the reusable first stage. Payload performance is again assessed by trajectory simulation. Then a detailed geometrical model is defined for first stage aerodynamics analysis and descent trajectory calculation. Results of the descent trajectory simulation as e.g. mechanical and thermal loads, range to the launch site and fly-back fuel mass are fed back to the mass model and payload performance can again be assessed by ascent trajectory calculation. An update on center of gravity position impacts the aerodynamics of the first stage and requires a reassessment of its aerodynamic performance and trimmability both for hypersonic reentry as well as the subsonic flight back to the launch site. Changes on geometry and mass model in turn may require changes on the staging and further iterations. This iterative approach is continued until the required payload target is reached, the desired first stage separation conditions are met, the aerodynamic performance is appropriate and the required mechanical and thermal load constraints are respected. An overview on the general, iterative preliminary design approach is shown in Figure 1.

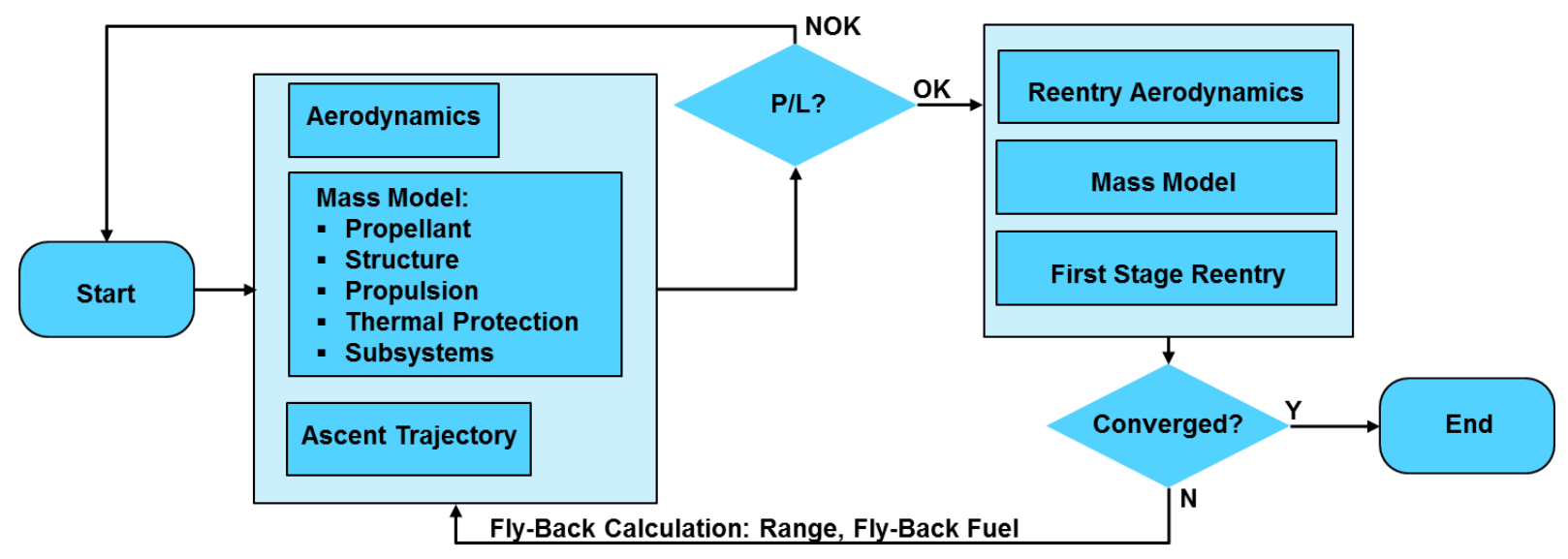

Figure 1: Iterative Preliminary Design Approach - Stage Fly Back

\section{General Architecture - Basic Assumptions}

In the following the general architecture, assumptions and simplifications applied to all considered configurations are described. The general architecture of the ascent configuration consists of a winged, reusable first stage with two expendable upper stages on top of it. This serial staging, linear architecture is shown in Figure 2. One diameter is assumed for all three stages. The reusable first stage and the expendable stages are connected with an interstage structure covering the nose section of the first stage. For the mass models of expendable stages a system margin of $10 \%$ is used for all subsystems excluding propulsion. For the reusable stage a system margin of $14 \%$ is used for all subsystems excluding propulsion. For the propulsion subsystem a system margin of $12 \%$ is used for both expendable and reusable stages. For all configurations studied, fuel reserves of $0.9 \%$, liquid residuals of $0.3 \%$ and gaseous residuals of 
$0.16 \%$ of the nominal ascent propellant mass are foreseen for the reusable first stage. In case of stage fly-back a margin of $20 \%$ is used for the calculated fly-back fuel mass.

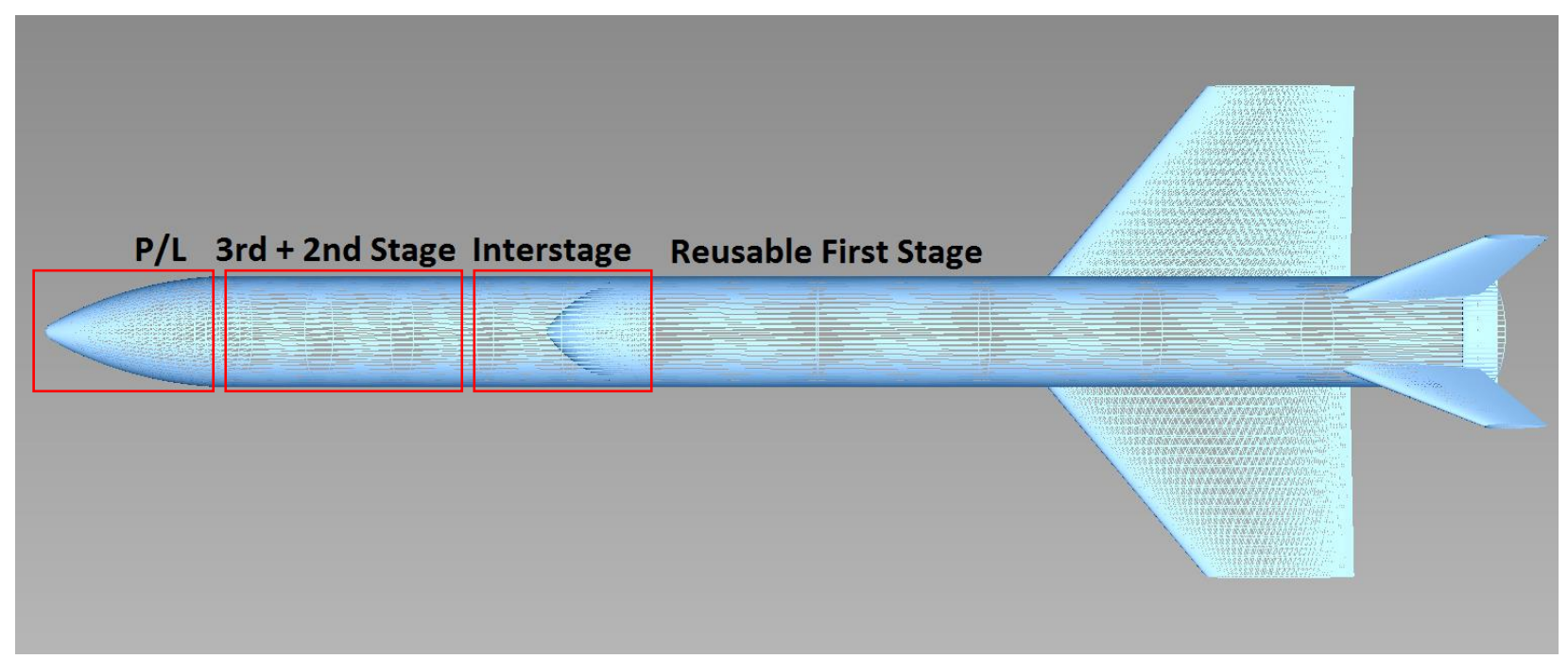

Figure 2: Launcher General Architecture

The modeling of stage masses is either based on simple, propellant loading dependent relations for structural indices or more detailed, empirical mass estimation methods allowing to estimate the mass of different components of vehicle structure, propulsion, thermal protection system and subsystems based on component and/or vehicle geometry and stage loads. For expendable upper stages only structural index functions are used. Structural index functions for LH2/LOX expendable stages used for this study are shown in Figure 3, [5]. These functions are based on existing expendable LH2/LOX stages for different propellant load ranges.

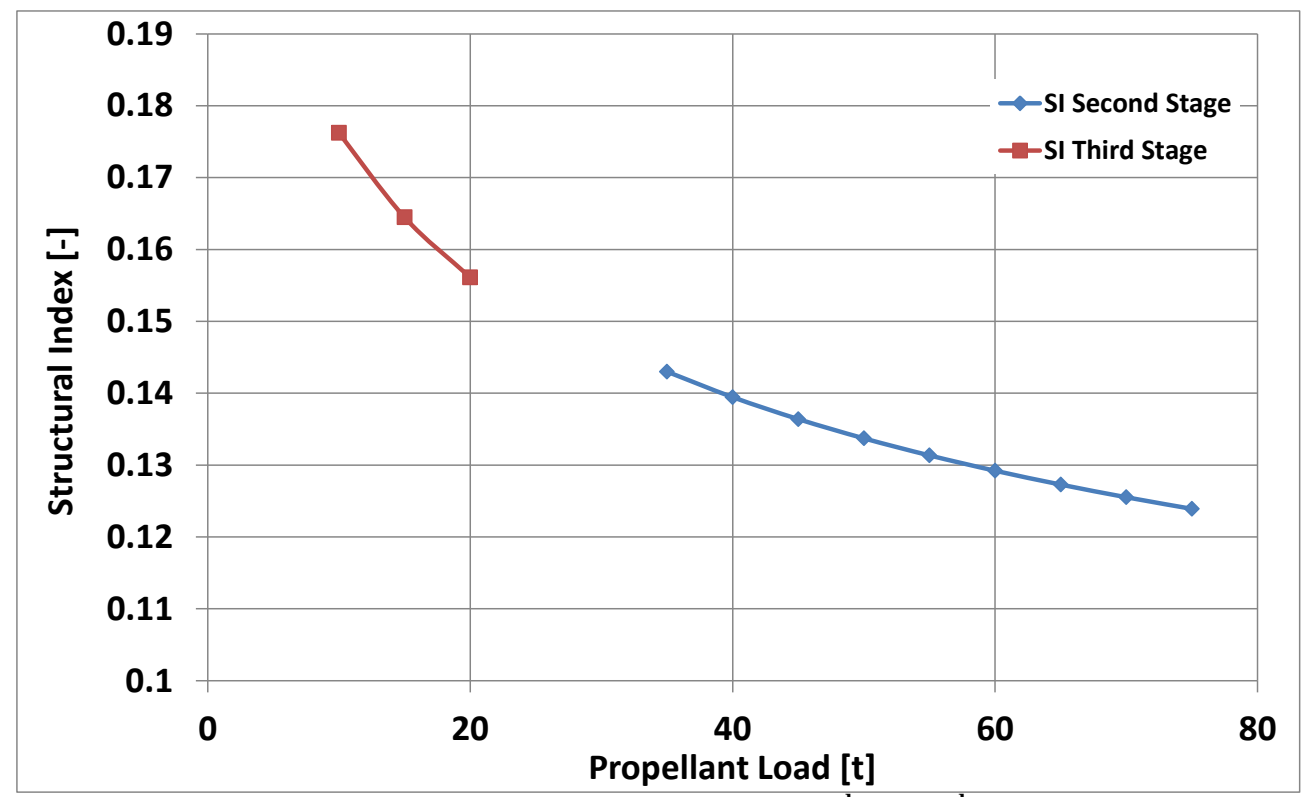

Figure 3: Structural Index Relations $2^{\text {nd }}$ and $3^{\text {rd }}$ Stage

The structural index definition underlying the functions shown in Figure 3 describes structural index as the ratio between stage dry mass and stage total propellant loading. Stage dry mass is 
considered without engine, interstage structure and fairing. Stage total propellant loading includes ascent, reserve and residual propellant.

The aerodynamics of the ascent configuration is modeled with DATCOM derived methods for the complete Mach number regime. These methods allow the analysis of simple fuselage and wing geometries. Fuselage aerodynamic characteristics are determined based on slender body theory whereas those of the wing are assessed based on empirical methods. For a fuselage-wing combination a superposition of fuselage and wing results is done. First stage reentry aerodynamics is modeled with DATCOM derived methods for subsonic, transonic and supersonic Mach number regimes. For the hypersonic Mach number regime surface inclination methods are used. A similar geometry is used for all reusable first stages both in terms of stage length to diameter ratio as well as wing relative parameters. The geometry is scaled for different stage diameters and lengths based on the same relative dimensions. As for the LFBB concept ([1], [2]) the RAE2822 airfoil is used for the first stage's single delta wing in all configurations. To achieve trimmed conditions within the entire atmospheric flight regime the reusable first stage has aerodynamic control surfaces in form of wing flaps and a body flap.

The rocket propulsion system of the reusable first stage is in all cases based on a LH2/LOX engine designed for the DLR-SART concept SpaceLiner. For these engines a Full-Flow Staged Combustion Cycle and a $16 \mathrm{MPa}$ thrust chamber pressure have been defined. The main characteristics are summarized in Table 1. Further details can be found in [6]. It is important to note that the number of engines on the first stage and the number of air-breathing engines vary whereas in all cases considered only one of the second and third stage engines described below is used. Additionally in contrast to ascent propellant loading on the first stage propellant mass for second and third stages is kept constant between the two return options and only does vary with separation Mach number.

\begin{tabular}{|l|c|}
\hline \multicolumn{2}{|c|}{ First Stage Propulsion System Characteristics } \\
\hline Thrust Chamber Pressure [MPa] & 16 \\
\hline Mixture Ratio [-] & 6.0 \\
\hline Vacuum Thrust [kN] & 2206 \\
\hline Sea Level Thrust [kN] & 1961 \\
\hline Vacuum Specific Impulse [s] & 437 \\
\hline Sea Level Specific Impulse [s] & 389 \\
\hline Mass Flow [kg/s] & 514.6 \\
\hline Nozzle Expansion Ratio & 33 \\
\hline
\end{tabular}

Table 1: First Stage Propulsion System Characteristics

The second stage engine is also a staged combustion cycle engine continuously scaled to achieve an axial acceleration of $0.8 \mathrm{~g}$ at stage ignition. Its main characteristics are given in Table 2 .

\begin{tabular}{|l|c|c|c|}
\hline \multicolumn{4}{|c|}{ Second Stage Propulsion System Characteristics } \\
\hline Separation Mach Number & 12 & 9 & 6 \\
\hline Vacuum Thrust [kN] & 540 & 720 & 1035 \\
\hline Vacuum Specific Impulse [s] & 458 & 458 & 458 \\
\hline Mass Flow [kg/s] & 120 & 160 & 230 \\
\hline
\end{tabular}

Table 2: Second Stage Propulsion System Characteristics 
The third stage rocket propulsion is a derivative of the Vinci engine with shortened nozzle and consists of an expander cycle LH2/LOX engine with $175 \mathrm{kN}$ thrust and 452 s specific impulse in vacuum. Its main characteristics are summarized in Table 3.

\begin{tabular}{|l|c|}
\hline \multicolumn{2}{|c|}{ Third Stage Propulsion System Characteristics } \\
\hline Mixture Ratio [-] & 5.8 \\
\hline Vacuum Thrust [kN] & 175 \\
\hline Vacuum Specific Impulse [s] & 452 \\
\hline Mass Flow [kg/s] & 39.5 \\
\hline
\end{tabular}

Table 3: Third Stage Propulsion System Characteristics

The air breathing engines for the fly-back return option are modified EJ200 engines (without afterburner) of MTU Aero Engines. These engines have already been foreseen for Ariane 5 Liquid Fly Back Booster studies (see [1], [2]), might be adapted for operation with hydrogen and are found favorable due to their high specific thrust and thrust to weight ratio as compared to e.g. civil aviation engines. Its main characteristics at sea level conditions are summarized in Table 4.

\begin{tabular}{|l|c|}
\hline \multicolumn{2}{|c|}{ Air-Breathing Propulsion System Characteristics } \\
\hline Sea Level Thrust [kN] & 53.5 \\
\hline Sea Level SFC [g/kN s] & 8.0 \\
\hline
\end{tabular}

Table 4: Air-Breathing Propulsion Characteristics

The assumed launch site for all configurations is Kourou with coordinates shown in Table 5. The target orbit is a Geostationary Transfer Orbit with orbital parameters shown in Table 6.

\begin{tabular}{|c|c|c|}
\hline Longitude $\left[{ }^{\circ}\right]$ & Latitude $\left[{ }^{\circ}\right]$ & Altitude $[\mathrm{km}]$ \\
\hline-52.769 & 5.240 & 0 \\
\hline
\end{tabular}

Table 5: Launch Site Coordinates

\begin{tabular}{|c|c|c|c|}
\hline & Perigee Altitude [km] & Apogee Altitude [km] & Inclination [ $\left.{ }^{\circ}\right]$ \\
\hline GTO & 250 & 35786 & 6.0 \\
\hline
\end{tabular}

Table 6: Target GTO Parameters

Limitations in dynamic pressure, heat flux, axial and normal acceleration have to be respected both during ascent as well as reentry flight. Maximum allowed values for these parameters are summarized in Table 7.

\begin{tabular}{|l|c|}
\hline \multicolumn{2}{|c|}{ Maximum Allowed Loads } \\
\hline Dynamic Pressure [kPa] & 90 \\
\hline Stagnation Point Heat Flux [kW/m²] & 600 \\
\hline Normal Acceleration (reentry) [g] & 4 \\
\hline Axial Acceleration (ascent) [g] & 4 \\
\hline
\end{tabular}

Table 7: Maximum Allowed Loads during Ascent and Reentry Flight

To respect the axial acceleration constraint during ascent flight first stage engines are throttled whereas the normal acceleration constraint requires angle of attack control. The ascent trajectory is optimized with the DLR-SART tool TOSCA to maximize the payload delivered to the target orbit. For the reentry flight quasi-optimal flight control methods are used. The normal 
acceleration is controlled using an integral control law. For stage fly-back minimum fuel consumption is achieved by flying along the orthodrome and at the lowest possible fuel consumption per range. The quasi-optimal control methods applied within this study for reentry and powered return flight are described in [7].

Standard atmosphere and a spherical gravitational model are used for all trajectory calculations.

\section{Stage Fly-Back}

Stage fly-back, as understood within this analysis, stands for a winged, reusable first stage using air-breathing propulsion for a powered flight back to the launch site. After separation the first stage re-enters the atmosphere, performs a turn and reaches conditions allowing the ignition of air-breathing engines. In the following, results of preliminary design computations for configurations with a reusable first stage having separation Mach numbers of 6,9 and 12 are presented.

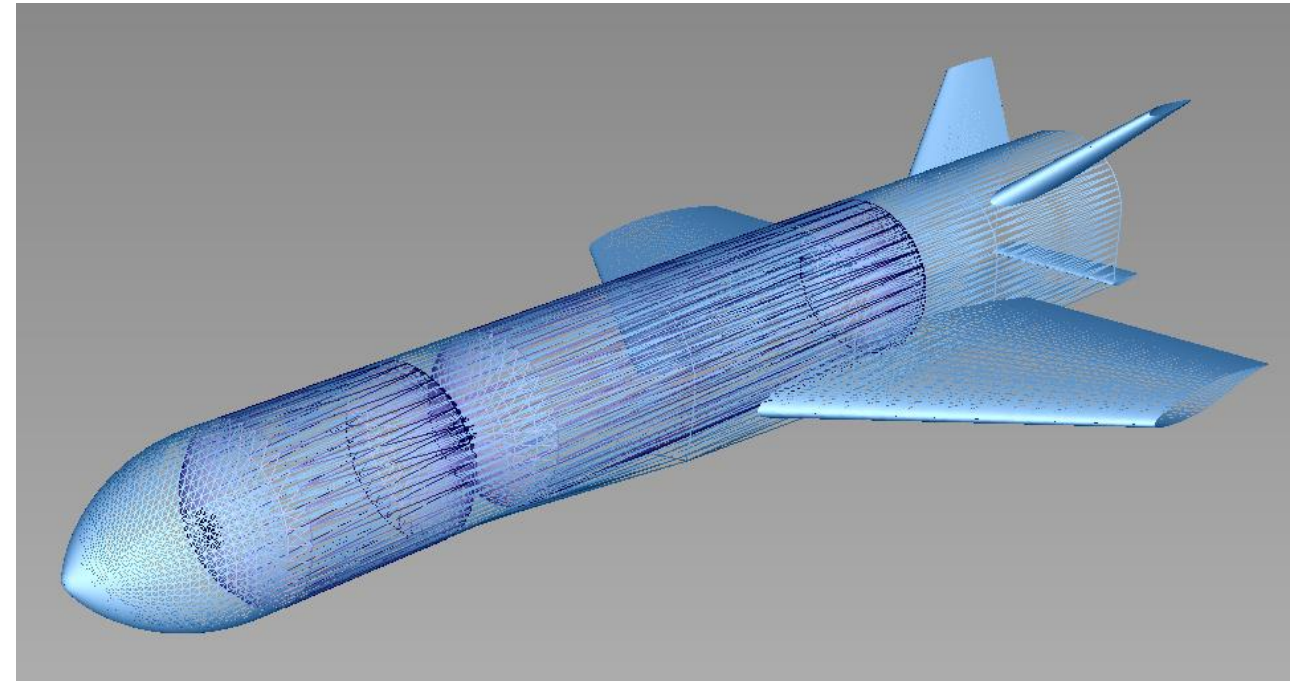

Figure 4: Reusable First Stage - Separation Mach Number 12

The configuration with a first stage separation Mach number of 12 is referred to as $\mathrm{H} 355 \mathrm{H} 35$ $\mathrm{H} 18$ having an ascent propellant loading of 355 metric tons of LH2/LOX propellant for the first stage, 35 metric tons for the second stage and 18 metric tons for the third stage. The stage diameter is $6.4 \mathrm{~m}$, the overall length of the ascent configuration is $83.2 \mathrm{~m}$. The geometry of the reusable first stage with a length of $54.2 \mathrm{~m}$ and a wingspan of $29 \mathrm{~m}$ is shown in Figure 4 . As for all other configurations the tanks are separated with the LOX tank being in the forward position. This configuration is propelled by four rocket engines. The six air-breathing engines are located in the nose segment while the fly back tanks are in the aft segment of the stage. The single delta wing has a sweep of $40 \mathrm{deg}$ and $17.9 \mathrm{~m}$ root chord length.

The lift-off mass of the three stage ascent configuration delivering $7500 \mathrm{~kg}$ of payload into Geostationary Transfer Orbit is 539.2 metric tons. The mass breakdown is shown in Table 8 . Structural index values are given including engines, interstage structure and fairing. Starting in Kourou in eastern direction maximum dynamic pressure of $32 \mathrm{kPa}$ is seen $58 \mathrm{~s}$ into the flight at an altitude of $9.8 \mathrm{~km}$ and a Mach number of 1.3 . Peak stagnation point heating of $39 \mathrm{~kW} / \mathrm{m}^{2}$ is encountered after $134 \mathrm{~s}$ at an altitude of $52.9 \mathrm{~km}$. Stagnation point heating both for the ascent and descent is estimated using an empirical relation. For this and all other configurations the nose 
radius of both the ascent configuration's payload fairing and the reusable first stage's nose structure is $0.5 \mathrm{~m}$. After reaching a velocity of $3.219 \mathrm{~km} / \mathrm{s}$ and a Mach number of 12 the first stage separates at an altitude of $89 \mathrm{~km}$. Trajectory parameters of the H355 H35 H18 ascent flight are shown in Figure 5.

\begin{tabular}{|c|c|}
\hline \multicolumn{2}{|c|}{ Stage 1 H355 - Structural Index incl. Engines and Interstage $22 \%$} \\
\hline Dry Mass & $83500 \mathrm{~kg}$ \\
\hline Fly-Back Propellant (incl. $20 \%$ reserves) & $20000 \mathrm{~kg}$ \\
\hline Stage Gross Lift Off Mass & $463300 \mathrm{~kg}$ \\
\hline \multicolumn{2}{|c|}{ Stage 2 H35 - Structural Index incl. Engine and Interstage $21.6 \%$} \\
\hline Dry Mass & $7800 \mathrm{~kg}$ \\
\hline Stage Gross Lift Off Mass & $44000 \mathrm{~kg}$ \\
\hline \multicolumn{2}{|c|}{ Stage $3 \mathrm{H18}$ - Structural Index incl. Engine and Fairing $30.9 \%$} \\
\hline Dry Mass (2000 kg Fairing) & $5800 \mathrm{~kg}$ \\
\hline Stage Gross Lift Off Mass (7500 kg Payload) & $31900 \mathrm{~kg}$ \\
\hline Total Lift Off Mass & $539200 \mathrm{~kg}$ \\
\hline
\end{tabular}

Table 8: Mass Breakdown H355 H35 H18 Configuration
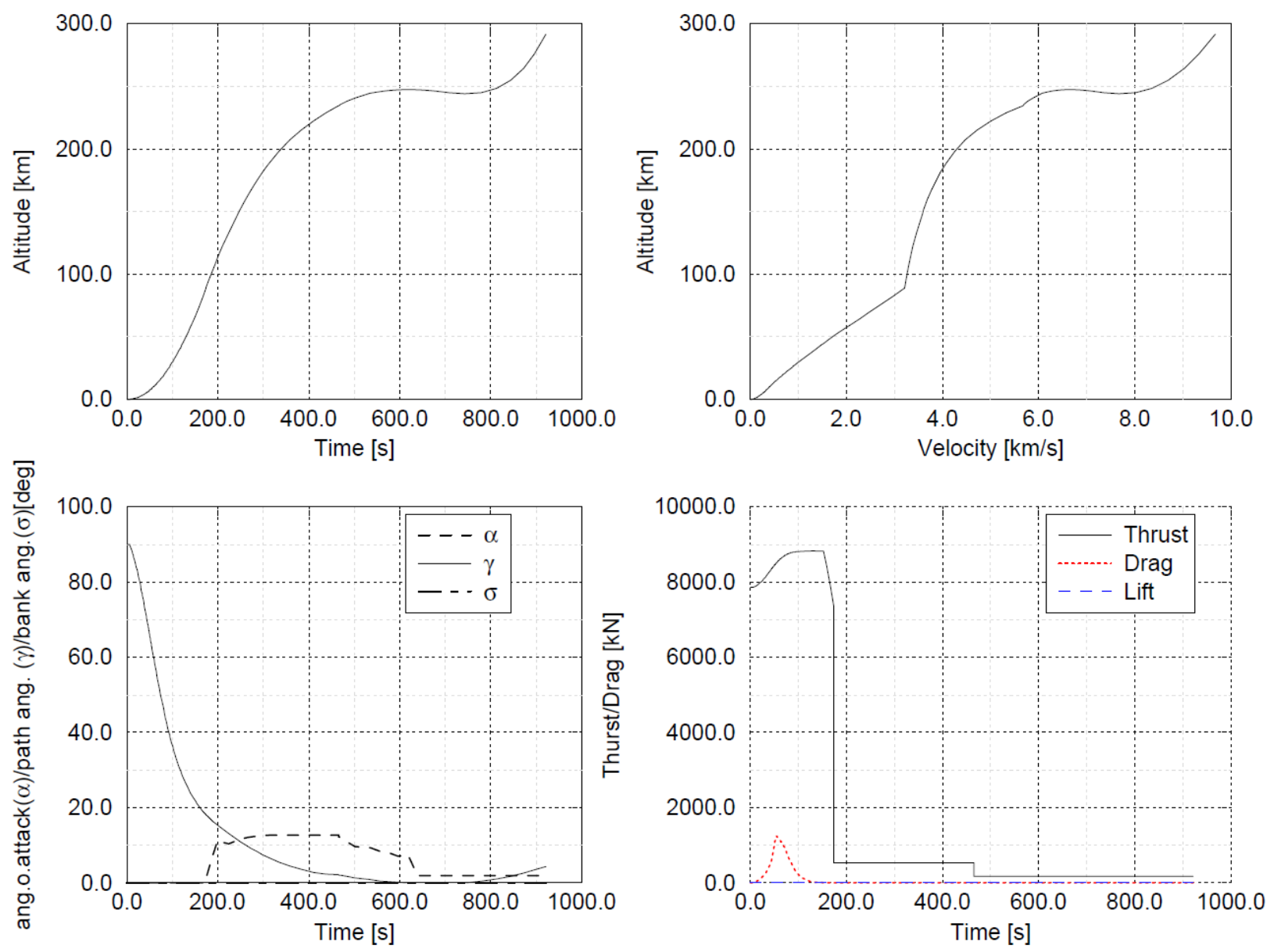

Figure 5: Ascent Trajectory H355 H35 H18 
Following separation the reusable first stage reaches a maximum altitude of almost $160 \mathrm{~km}$, performs a reentry into the atmosphere and after turning into the direction of the launch site begins a powered flight towards Kourou. A peak dynamic pressure of $90 \mathrm{kPa}$ and a maximum stagnation point heat flux of $570 \mathrm{~kW} / \mathrm{m}^{2}$ are reached. For the point of maximum stagnation point heat flux along the reentry trajectory a distribution of heat flux was determined with the surface inclination tool used to model hypersonic aerodynamics. The point of maximum stagnation heating is in $29.7 \mathrm{~km}$ altitude at a Mach number of 8.5 and an angle of attack value of 7.9 degrees. The results in the nose region are comparable to the values resulting from the empirical heat flux formula. However in the regions of leading edges significantly higher values of up to $780 \mathrm{~kW} / \mathrm{m}^{2}$ are found. The resulting heat flux distribution is shown in Figure 6. Altitude, dynamic pressure and stagnation point heating histories are shown in Figure 7.

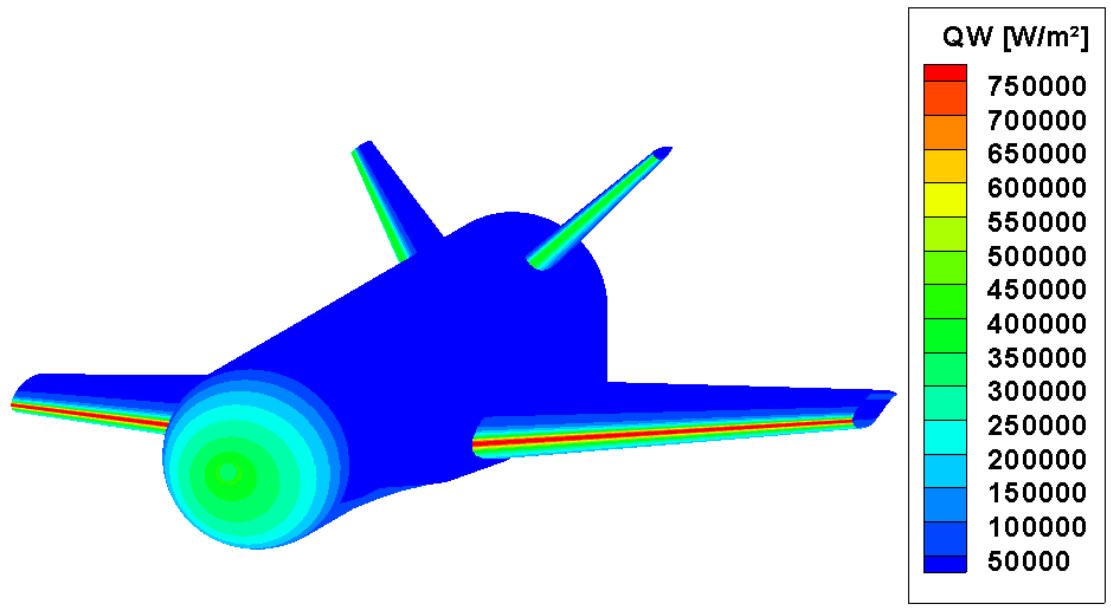

Figure 6: Heat Flux Distribution at Maximum Stagnation Point Heating

From a structural point of view, both the normal acceleration load and peak dynamic pressure are of utmost importance. On the other hand performing the turning maneuver as soon as possible is favorable with respect to the range to be covered during return flight. For this reason in case of $\mathrm{H} 355$ and all other configurations the turning maneuver is performed as soon as possible but in line with the general constraints of $4 \mathrm{~g}$ for normal acceleration, $90 \mathrm{kPa}$ for dynamic pressure and $600 \mathrm{~kW} / \mathrm{m}^{2}$ for stagnation point heat flux. Turning is performed to the right in all cases by banking with the maximum allowed banking angle being $50 \mathrm{deg}$. After separation while dynamic pressure is low the angle of attack is controlled by RCS and increases to its maximum allowed value of $40 \mathrm{deg}$. After switching back to aerodynamic control with increasing dynamic pressure during reentry the angle of attack is reduced to not violate the normal load constraint and stabilizes at a value allowing return flight with good aerodynamic performance. Histories of bank angle magnitude, angle of attack and normal acceleration are shown in Figure 8. 


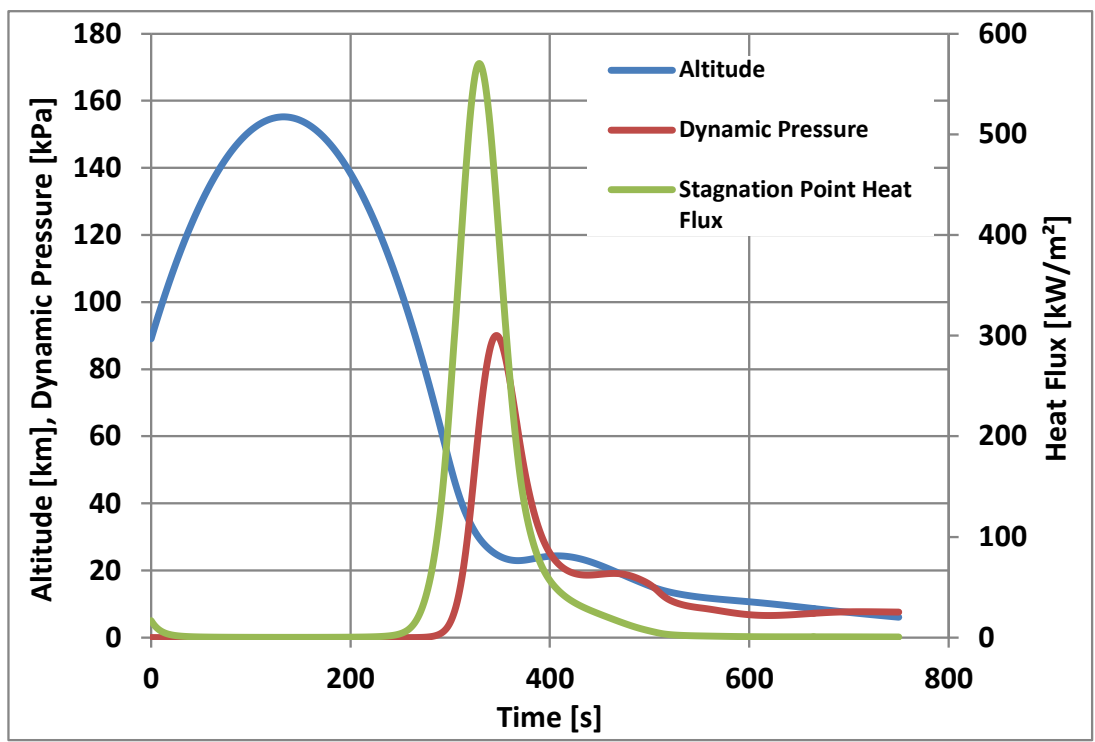

Figure 7: H355 Reentry Flight Parameters

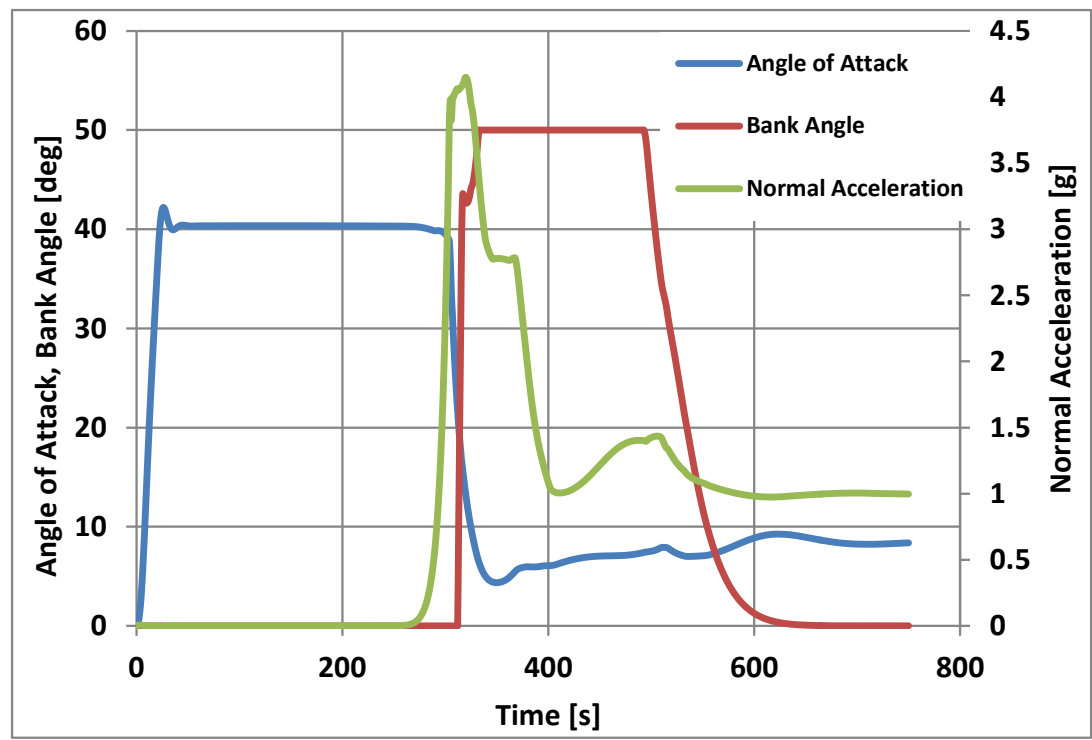

Figure 8: Normal Acceleration, Angle of Attack and Bank Angle Magnitude during H355 Reentry

After reentry air-breathing engines are providing the necessary thrust for the return flight back to the launch site. Following the turn a distance of $1200 \mathrm{~km}$ is to be covered. During powered flight an optimized profile of altitude and Mach number is followed that ensures flight at minimum fuel consumption per range, details see [7]. The fly-back fuel mass required is to a big extent determined by the distance and the aerodynamic performance of the reusable first stage. Control surface deflections to achieve trimmed flight conditions significantly decrease the aerodynamic performance of the reusable stage. In addition, center of gravity motion is also requiring increasing the flap deflections due to the growing distance between center of gravity and center of pressure with decreasing fuel mass in the fly back tanks located in the rear section of the stage. The lift to drag ratio for the H355 stage at Ma 0.4 for untrimmed and trimmed configurations at full and empty fly-back tanks is shown in Figure 9 and reveals a significant performance loss due to the flap deflections required to trim the vehicle. 


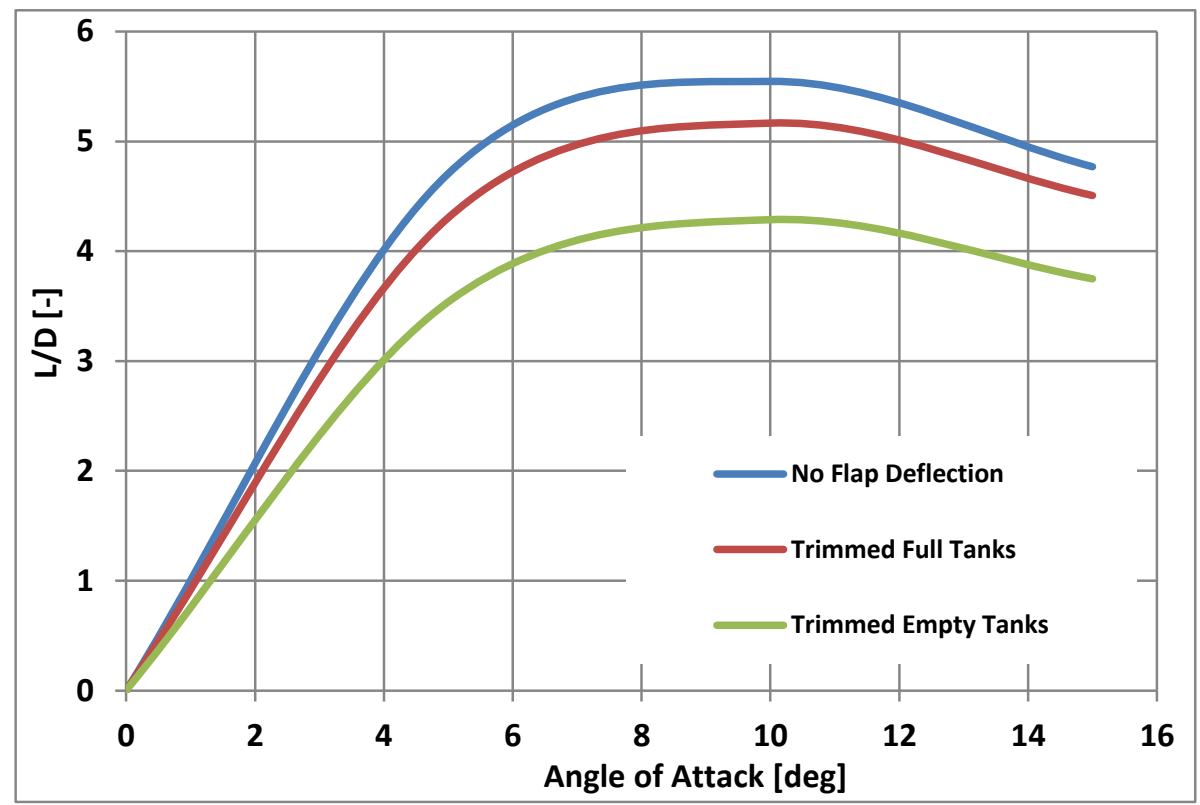

Figure 9: Aerodynamic Performance $\mathrm{H355}$

Maximum L/D is found at 10 deg angle of attack. Histories of altitude, Mach number and wing flap deflection magnitude necessary for trimmed conditions during the $2.5 \mathrm{~h}$ long return flight are shown in Figure 10. The sign of the wing flap deflection is negative, i.e. upwards. It is important to note that the body flap is deflected only in a positive sense and is used only for the hypersonic part of the flight.

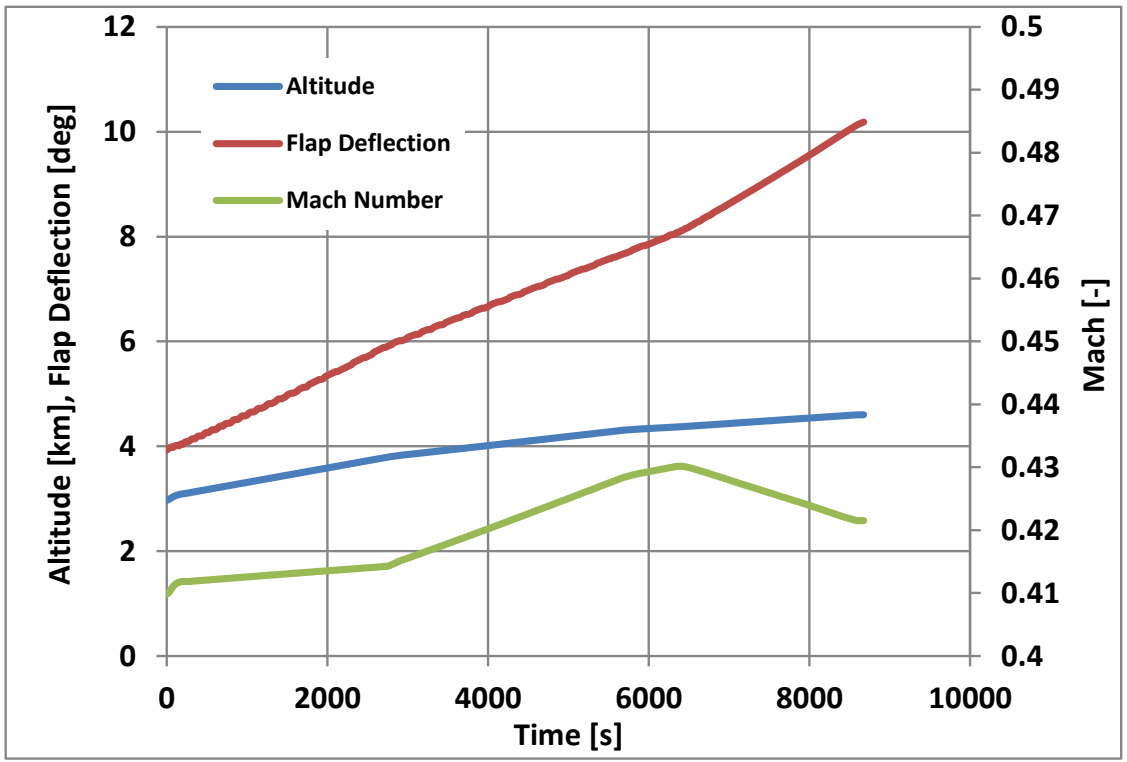

Figure 10: Altitude, Mach Number and Flap Deflection Magnitude during Return Flight

The fly-back configuration in the class of separation Mach number 9 is a H280 H50 H19 staging with 280 metric tons of LH2/LOX in the first reusable stage, 50 tons in the second stage and 19 tons in the third stage. The stage diameter is $5.8 \mathrm{~m}$, the total length of the ascent configuration is $78 \mathrm{~m}$ and the reusable first stage measures $48.8 \mathrm{~m}$ in length with a wingspan of $26 \mathrm{~m}$. The root 
chord length of the single delta wing is $16.1 \mathrm{~m}$. The configuration employs three first stage rocket engines and has five air-breathing engines for powered fly-back to the launch site.

The lift-off mass of the three stage ascent configuration delivering $7510 \mathrm{~kg}$ of payload into Geostationary Transfer Orbit is 451.4 metric tons. The mass breakdown is shown in Table 9.

\begin{tabular}{|l|c|}
\hline \multicolumn{2}{|c|}{ Stage 1 H280 - Structural Index incl. Engines and Interstage 21.7 \% } \\
\hline Dry Mass & $63700 \mathrm{~kg}$ \\
\hline Fly-Back Propellant (incl. 20 \% reserves) & $9300 \mathrm{~kg}$ \\
\hline Stage Gross Lift Off Mass & $356800 \mathrm{~kg}$ \\
\hline \multicolumn{2}{|c|}{ Stage 2 H50 - Structural Index incl. Engine and Interstage 19 \% } \\
\hline Dry Mass & $9800 \mathrm{~kg}$ \\
\hline Stage Gross Lift Off Mass & $61500 \mathrm{~kg}$ \\
\hline \multicolumn{2}{|c|}{ Stage 3 H19 - Structural Index incl. Engine and Fairing $29.9 \%$} \\
\hline Dry Mass (2000 kg Fairing) & $5900 \mathrm{~kg}$ \\
\hline Stage Gross Lift Off Mass (7510 kg Payload) & $33100 \mathrm{~kg}$ \\
\hline Total Lift Off Mass & $\mathbf{4 5 1 4 0 0 ~ k g}$ \\
\hline
\end{tabular}

Table 9: Mass Breakdown H280 H50 H19 Configuration

In the separation Mach number 6 class iteration converged to a H210 H73 H17 configuration with a total lift-off mass of 391.9 metric tons. In this case the stage diameter is at $5.3 \mathrm{~m}$, the ascent configuration total length is $78.5 \mathrm{~m}$ and reusable first stage length is at $43.9 \mathrm{~m}$. First stage wing spans $23.5 \mathrm{~m}$ with a root chord length of $14.5 \mathrm{~m}$. Three first stage engines and again five air-breathing engines are used. The mass breakdown is shown in Table 10.

\begin{tabular}{|l|c|}
\hline \multicolumn{2}{|c|}{ Stage 1 H210 - Structural Index incl. Engines and Interstage 25.6 \% } \\
\hline Dry Mass & $55500 \mathrm{~kg}$ \\
\hline Fly-Back Propellant (incl. 20 \% reserves) & $4540 \mathrm{~kg}$ \\
\hline Stage Gross Lift Off Mass & $272900 \mathrm{~kg}$ \\
\hline \multicolumn{2}{|c|}{ Stage $\mathbf{2}$ H73 - Structural Index incl. Engine and Interstage 17 \% } \\
\hline Dry Mass & $12800 \mathrm{~kg}$ \\
\hline Stage Gross Lift Off Mass & $88200 \mathrm{~kg}$ \\
\hline \multicolumn{2}{|c|}{ Stage 3 H17 - Structural Index incl. Engine and Fairing 31.9 \% } \\
\hline Dry Mass (2000 kg Fairing) & $5600 \mathrm{~kg}$ \\
\hline Stage Gross Lift Off Mass (7500 kg Payload) & $30700 \mathrm{~kg}$ \\
\hline Total Lift Off Mass & $\mathbf{4 5 1 4 0 0 ~ k g}$ \\
\hline
\end{tabular}

Table 10: Mass Breakdown H210 H73 H17 Configuration

\section{Stage In-Air Capturing}

Techniques of powered return flight obligate a propulsion system and its fuel, which raises the stage's inert mass. The patented "In-air-capturing" [3] offers a different approach with better performance: The winged reusable stages are to be caught in the air, and towed back to their launch site without any necessity of an own propulsion system [8]. Inert mass of such a reusable stage is significantly reduced.

A schematic of the reusable stage's full operational circle is shown in Figure 11. At the launcher's lift-off the capturing aircraft is waiting at a downrange rendezvous area. After its MECO the 
reusable winged stage is separated from the rest of the launch vehicle and afterwards performs a ballistic trajectory, soon reaching denser atmospheric layers. At around $20 \mathrm{~km}$ altitude it decelerates to subsonic velocity and rapidly loses altitude in a gliding flight path. At this point a reusable returning stage usually has to initiate the final landing approach or has to ignite its secondary propulsion system.

Within the in-air-capturing method, the reusable stage is awaited by an adequately equipped large capturing aircraft (most likely fully automatic and unmanned), offering sufficient thrust capability to tow a winged launcher stage with restrained lift to drag ratio. Both vehicles have the same heading still on different flight levels. The reusable unpowered stage is approaching the airliner from above with a higher initial velocity and a steeper flight path, actively controlled by aerodynamic braking. The time window to successfully perform the capturing process is dependent on the performed flight strategy of both vehicles, but can be extended up to about two minutes. The entire maneuver is fully subsonic in an altitude range from around $8000 \mathrm{~m}$ to 2000 $\mathrm{m}$ [4]. The upper constraint is set by the requirement to reach full aerodynamic controllability of the winged stage. After successfully connecting both vehicles, the winged reusable stage is towed by the large carrier aircraft back to the launch site. Close to the airfield, the stage is released, and autonomously glides like a sailplane to earth.

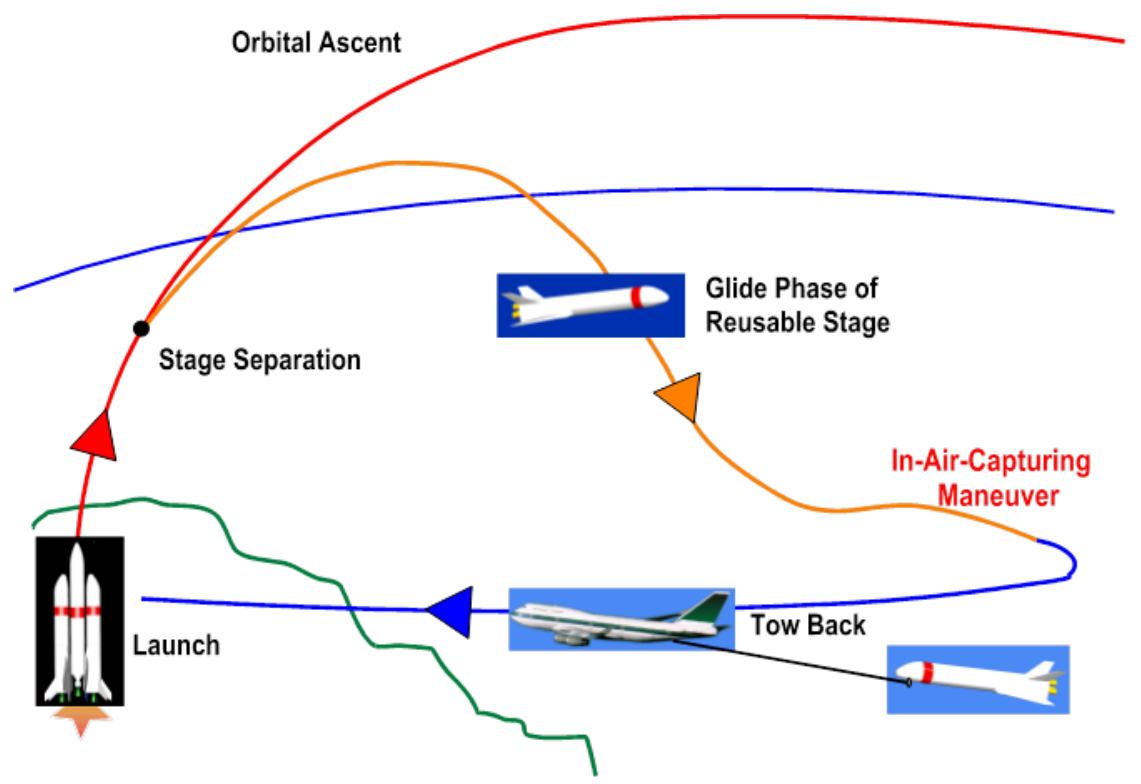

Figure 11: Schematic of the proposed in-air capturing

The selected flight strategy and the applied control algorithms show in simulations a robust behavior of the reusable stage to reach the capturing aircraft. In the nominal case the approach maneuver of both vehicles requires active control only by the gliding stage. Simulations (3DOF) regarding reasonable assumptions in mass and aerodynamic quality proof that a minimum distance below $200 \mathrm{~m}$ between RLV and aircraft can be maintained for up to two minutes [4]. The most promising capturing technique is using an aerodynamically controlled capturing device (ACCD), showing the best performance and lowest risk $[4,9]$.

After DLR had patented the "in-air-capturing"-method for future RLVs, two similar approaches have been proposed. However, those named mid-air retrieval or mid-air capturing are relying on parachute or parafoil as lifting devices for the reusable parts and helicopters as capturing aircraft. The first proposal was made by the Russian launcher company Khrunichev [10] and the most 
recent one by the American company ULA for its newly proposed Vulcan launcher. A parachute and helicopter based system is obviously less flexible and significantly less robust than the in-aircapturing based on winged RLV and winged aircraft. Consequently, the ULA proposal intends recovering not more than the first stage's engine bay instead of a full stage [11]. DLR is currently preparing for flight testing the "in-air-capturing"-method on a laboratory scale by using two fully autonomous vehicles. As in the case of stage fly-back in the following results of preliminary design computations for configurations with a reusable first stage having separation Mach numbers of 6, 9 and 12 are presented.

The largest of the configurations with a separation Mach number of approximately 12 is a $\mathrm{H} 223$ H35 H18 with 223 metric tons of LH2/LOX in the first stage, 35 tons of propellant in the second stage and 18 tons in the third stage. The stage diameter is $5.2 \mathrm{~m}$ with an overall length of the ascent configuration of $72.4 \mathrm{~m}$. The first stage has three rocket engines and is $43.4 \mathrm{~m}$ long with a wing span of $23.2 \mathrm{~m}$. In contrast to the fly-back configurations no powered return flight is performed by the stage and descent trajectory calculation stops after entering the atmosphere and performing a turn. The lift-off mass of the ascent configuration delivering $7500 \mathrm{~kg}$ of payload into Geostationary Transfer Orbit is 346.0 metric tons. The mass breakdown is shown in Table 11. Along the ascent trajectory maximum dynamic pressure of $47 \mathrm{kPa}$ is seen $51 \mathrm{~s}$ into the flight at an altitude of $10.3 \mathrm{~km}$ and a Mach number of 1.6. Peak stagnation point heating of $64 \mathrm{~kW} / \mathrm{m}^{2}$ is encountered after $115 \mathrm{~s}$ at an altitude of $49.1 \mathrm{~km}$. Figure 12 shows the ascent trajectory parameters of the $\mathrm{H} 223 \mathrm{H} 35 \mathrm{H} 18$ configuration.
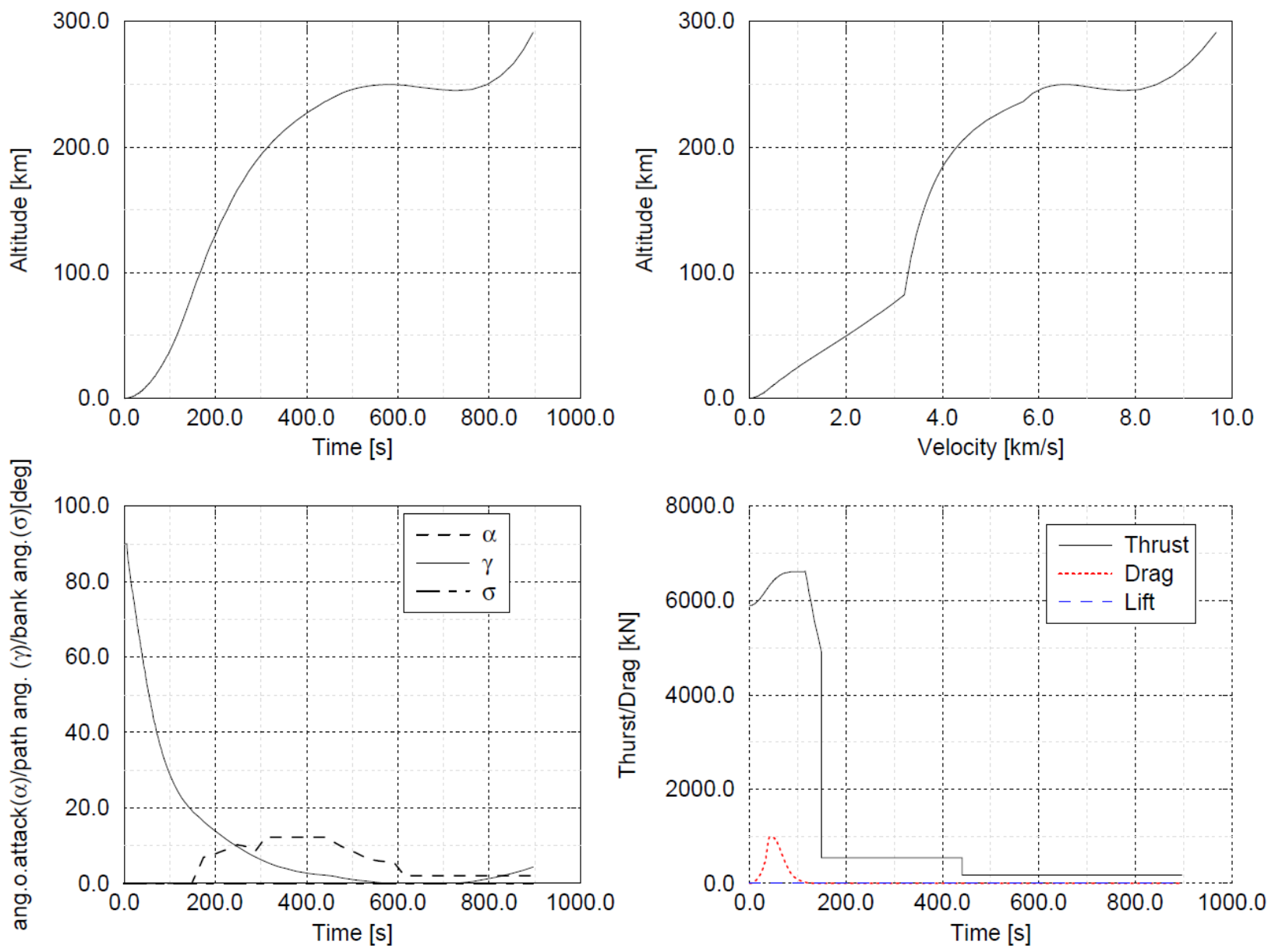

Figure 12: H223 H35 H18 Ascent Trajectory 


\begin{tabular}{|l|c|}
\hline \multicolumn{2}{|c|}{ Stage 1 H223 - Structural Index incl. Engines and Interstage 19.6 \% } \\
\hline Dry Mass & $44300 \mathrm{~kg}$ \\
\hline Stage Gross Lift Off Mass & $270300 \mathrm{~kg}$ \\
\hline \multicolumn{2}{|c|}{ Stage 2 H35 - Structural Index incl. Engine and Interstage 20.9 \% } \\
\hline Dry Mass & $7600 \mathrm{~kg}$ \\
\hline Stage Gross Lift Off Mass & $43800 \mathrm{~kg}$ \\
\hline \multicolumn{2}{|c|}{ Stage 3 H18 - Structural Index incl. Engine and Fairing $\mathbf{3 0 . 9} \%$} \\
\hline Dry Mass (2000 kg Fairing) & $5800 \mathrm{~kg}$ \\
\hline Stage Gross Lift Off Mass (7500 kg Payload) & $31900 \mathrm{~kg}$ \\
\hline Total Lift Off Mass & $\mathbf{3 4 6 0 0 0} \mathbf{~ k g}$ \\
\hline
\end{tabular}

Table 11: Mass Breakdown H223 H35 H18 Configuration

After separation the reusable first stage achieves a maximum altitude of more than $150 \mathrm{~km}$, performs a reentry into the atmosphere and turns towards the launch site reaching conditions that allow beginning the in-air capturing of the reusable stage. A peak dynamic pressure of $66 \mathrm{kPa}$ and a maximum stagnation point heat flux of $454 \mathrm{~kW} / \mathrm{m}^{2}$ are reached. Altitude, dynamic pressure and stagnation point heating histories are shown in Figure 13.

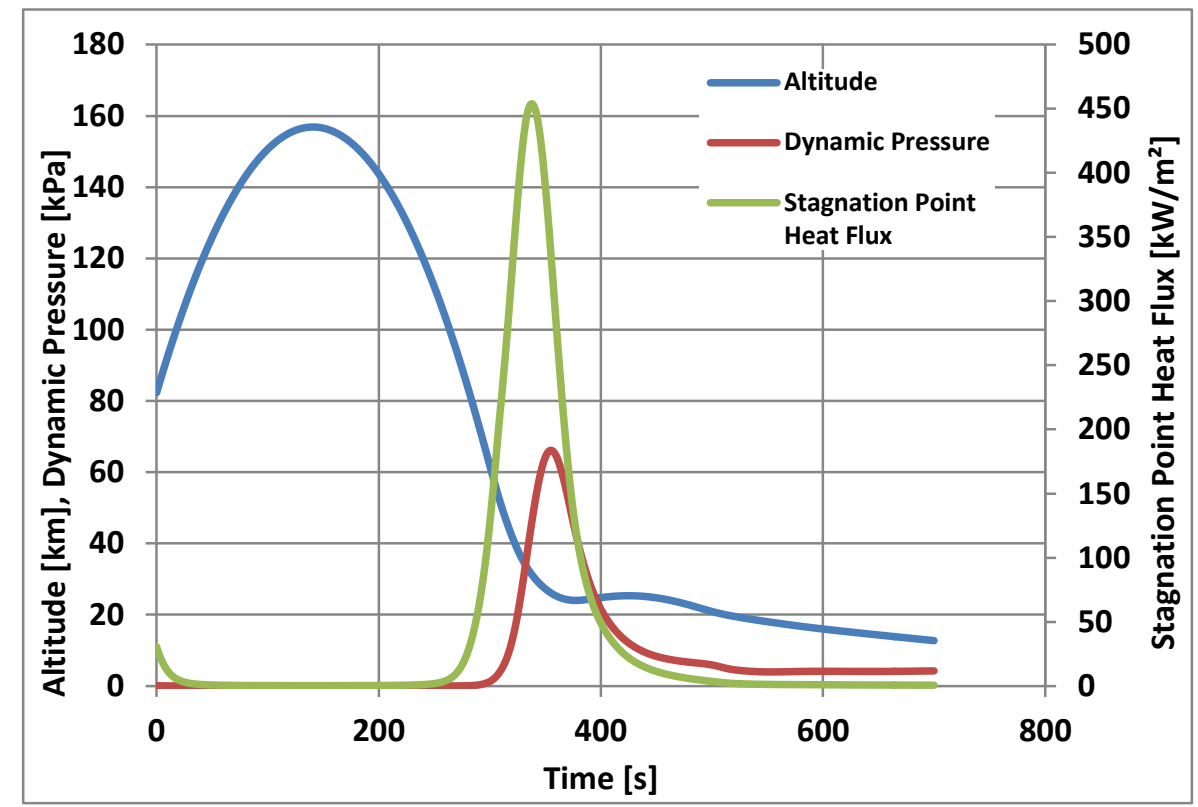

Figure 13: H223 Reentry Flight Parameters

The separation Mach 9 configuration has a H200 H50 H19 staging with a diameter of $5.1 \mathrm{~m}$ and an overall length of $73 \mathrm{~m}$. First stage length is $41.6 \mathrm{~m}$ with a wingspan of $22.3 \mathrm{~m}$ and a root chord length of $13.7 \mathrm{~m}$. The first stage uses three engines. The lift-off mass of the configuration is 339.8 metric tons including a payload mass of $7500 \mathrm{~kg}$. The mass breakdown of H200 H50 H19 is shown in Table 12.

Having a total lift-off mass of 337.2 metric tons including $7450 \mathrm{~kg}$ payload the H175 H73 H17 configuration is in the class of separation Mach 6. This configuration has a stage diameter of 4.9 $\mathrm{m}$ and a total length of $76.7 \mathrm{~m}$. First stage length is $40 \mathrm{~m}$ with a wingspan of $21.5 \mathrm{~m}$ and a root chord length of $13.2 \mathrm{~m}$. The mass breakdown of the configuration is shown in Table 13. 


\begin{tabular}{|l|c|}
\hline \multicolumn{2}{|c|}{ Stage 1 H200 - Structural Index incl. Engines and Interstage 21.1 \% } \\
\hline Dry Mass & $42700 \mathrm{~kg}$ \\
\hline Stage Gross Lift Off Mass & $245400 \mathrm{~kg}$ \\
\hline \multicolumn{2}{|c|}{ Stage 2 H50 - Structural Index incl. Engine and Interstage 18.7 \% } \\
\hline Dry Mass & $9700 \mathrm{~kg}$ \\
\hline Stage Gross Lift Off Mass & $61300 \mathrm{~kg}$ \\
\hline \multicolumn{2}{|c|}{ Stage 3 H19-Structural Index incl. Engine and Fairing 29.9} \\
\hline Dry Mass (2000 kg Fairing) & $5900 \mathrm{~kg}$ \\
\hline Stage Gross Lift Off Mass (7500 kg Payload) & $33100 \mathrm{~kg}$ \\
\hline Total Lift Off Mass & $\mathbf{3 3 9 8 0 0 ~ k g}$ \\
\hline
\end{tabular}

Table 12: Mass Breakdown H200 H50 H19 Configuration

\begin{tabular}{|l|c|}
\hline \multicolumn{2}{|c|}{ Stage 1 H175 - Structural Index incl. Engines and Interstage 23.1 \% } \\
\hline Dry Mass & $40900 \mathrm{~kg}$ \\
\hline Stage Gross Lift Off Mass & $218300 \mathrm{~kg}$ \\
\hline Stage 2 H73 - Structural Index incl. Engine and Interstage 17 \% \\
\hline Dry Mass & $12800 \mathrm{~kg}$ \\
\hline Stage Gross Lift Off Mass & $88200 \mathrm{~kg}$ \\
\hline \multicolumn{2}{|c|}{ Stage 3 H17 - Structural Index incl. Engine and Fairing 31.9 \% } \\
\hline Dry Mass (2000 kg Fairing) & $5600 \mathrm{~kg}$ \\
\hline Stage Gross Lift Off Mass (7450 kg Payload) & $30700 \mathrm{~kg}$ \\
\hline Total Lift Off Mass & $\mathbf{3 3 7 2 0 0} \mathbf{~ k g}$ \\
\hline
\end{tabular}

Table 13: Mass Breakdown H175 H73 H17 Configuration

\section{Comparison of Return Options - Conclusions}

In this section the different fly-back and in-air capturing configurations are compared in terms of their mass, dimensions, payload performance and loads. It is emphasized that the goal of this study is to quantify a comparison of stage fly-back and in-air capturing as first stage return options. The geometrical parameters of the different configurations are summarized in Table 14.

\begin{tabular}{|l|c|c|c|c|}
\hline & $\begin{array}{c}\text { Diameter } \\
{[\mathbf{m}]}\end{array}$ & Length [m] & First Stage Length [m] & Wingspan [m] \\
\hline Fly Back M 12 & 6.4 & 83.2 & 54.2 & 29 \\
\hline Fly Back M 9 & 5.8 & 78 & 48.8 & 26 \\
\hline Fly Back M 6 & 5.3 & 78.5 & 43.9 & 23.5 \\
\hline In-Air Capturing M 12 & 5.2 & 72.4 & 43.4 & 23.2 \\
\hline In-Air Capturing M 9 & 5.1 & 73 & 41.6 & 22.3 \\
\hline In-Air Capturing M 6 & 4.9 & 76.7 & 40 & 21.5 \\
\hline
\end{tabular}

Table 14: Summary of Configuration Dimensions

A Mach-Altitude plot is shown in Figure 14. It can be seen that the fly-back configurations are entering the atmosphere at lower altitudes with respect to the in-air capturing stages at the same Mach numbers. This is due to their higher reentry mass. As a consequence maximum dynamic 
pressure and stagnation point heat flux in case of the fly-back configurations is significantly higher than in case of the in-air capturing configurations as can be seen in Table 15.

\begin{tabular}{|c|c|c|}
\hline & $\begin{array}{c}\text { Max. Dyn. Pressure } \\
{[\mathrm{kPa}]}\end{array}$ & Max. Stagnation Point Heat Flux $\left[\mathrm{kW} / \mathrm{m}^{2}\right]$ \\
\hline Fly Back M 12 & 90 & 570 \\
\hline Fly Back M 9 & 86.6 & 382 \\
\hline Fly Back M 6 & 81.4 & 189 \\
\hline In-Air Capturing M 12 & 66.1 & 453.8 \\
\hline In-Air Capturing M 9 & 53.6 & 239 \\
\hline In-Air Capturing M 6 & 42.6 & 90.5 \\
\hline
\end{tabular}

Table 15: Maximum Loads during Reentry

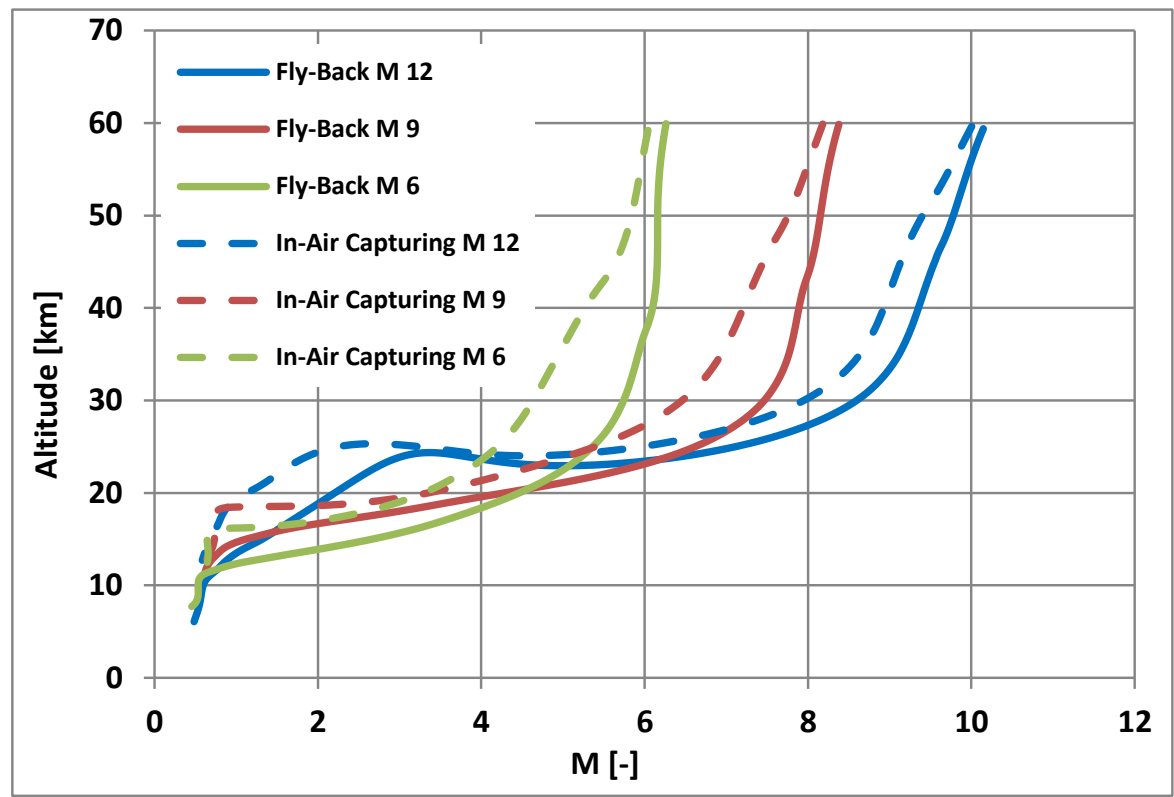

Figure 14: Reusable Stage Reentry Trajectories

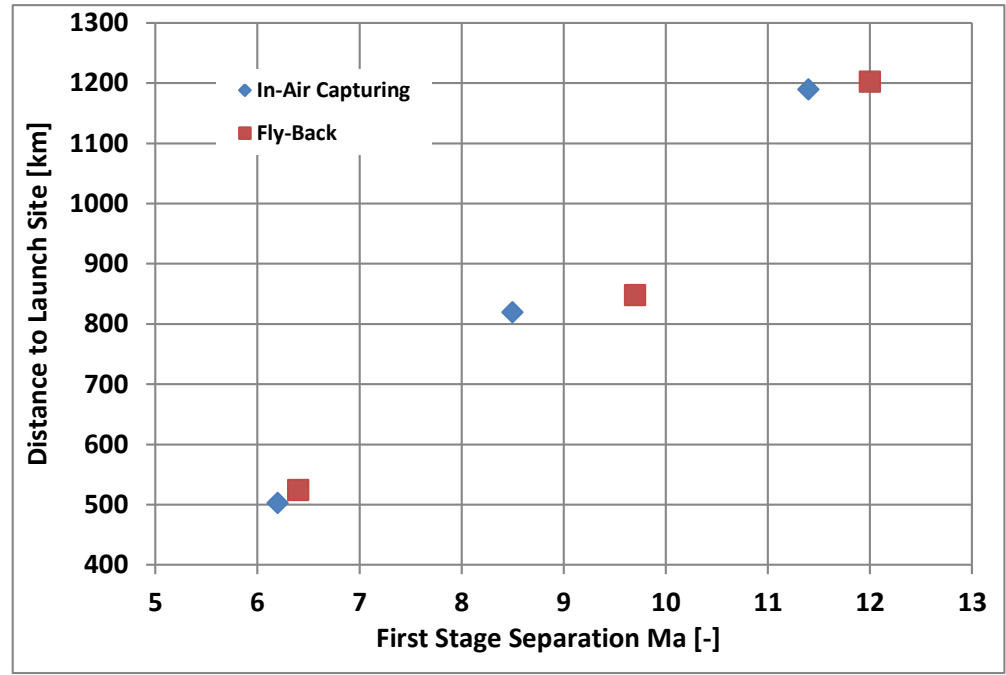

Figure 15: Distance to Launch Site 
Another important aspect of the comparison is the distance to the launch site that remains after reentry and turn maneuver. The distances span from $1200 \mathrm{~km}$ at separation Mach of 12 down to $500 \mathrm{~km}$ at separation Mach 6. However for the configurations analyzed a significant difference in distance to the launch site for a certain separation Mach number cannot be observed between the two return options. The evolution of distance to launch site with separation Mach number is shown in Figure 15. For the competiveness of the fly-back return option the fuel mass required for fly-back is an important factor. Its evolution is shown in Figure 16.

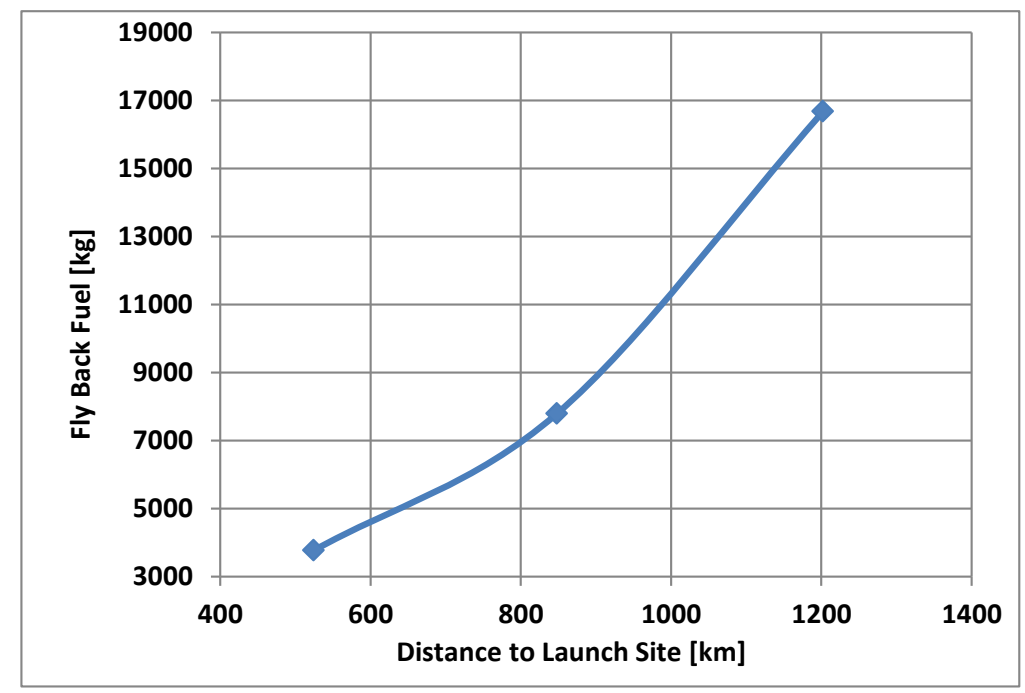

Figure 16: Fly Back Fuel Mass

Finally the comparison is done with respect to payload mass fraction and lift-off as well as stage mass. The payload mass fraction as the ratio between payload mass and total ascent configuration lift-off mass is shown in Figure 17.

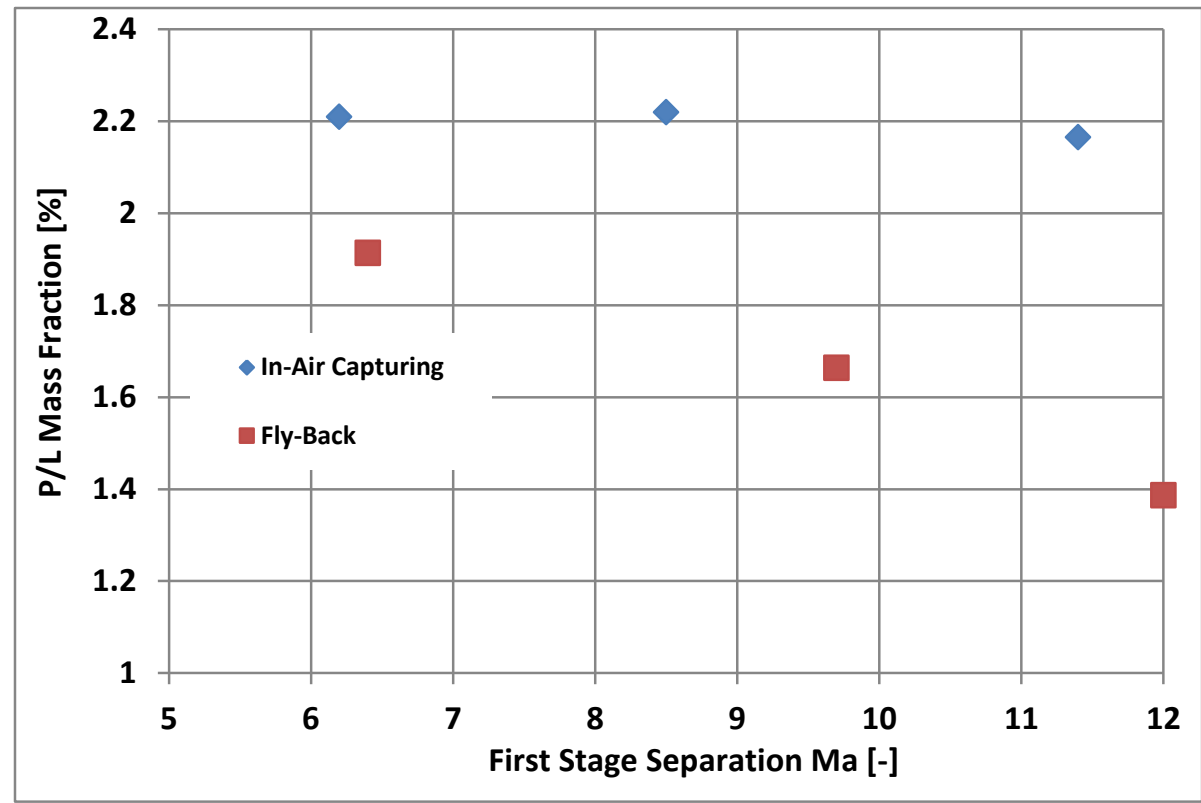

Figure 17: Payload Mass Fraction 
In case of in-air capturing the payload mass fraction remains almost constant at around $2.2 \%$. This is due to the fact that with increasing separation Mach numbers the reusable stages structural indices are decreasing while those of the expendable second stage are increasing. For the considered configurations these two effects to a certain extent balance each other and the payload mass fraction stays approximately constant. In case of fly-back, increasing separation Mach numbers lead to an increase in both fly-back fuel mass and also reusable stage dry mass because of bigger fly-back fuel tanks, stage size and eventually additional air-breathing as well as rocket engines. As a consequence payload mass fraction decreases from $1.9 \%$ to $1.4 \%$. This interpretation is supported by the comparison of stage lift-off masses between the two return options as shown in Figure 18. While in the case of in-air capturing total lift-off mass is almost constant, in case of fly-back both total lift-off mass and reusable stage lift-off mass are increasing. The ratio of in-air capturing to fly-back lift-off mass is going down from $86 \%$ to $64 \%$ with increasing first stage separation Mach number. This reduction emphasizes the advantages of the in-air capturing method with increasing separation Mach numbers of reusable stages.

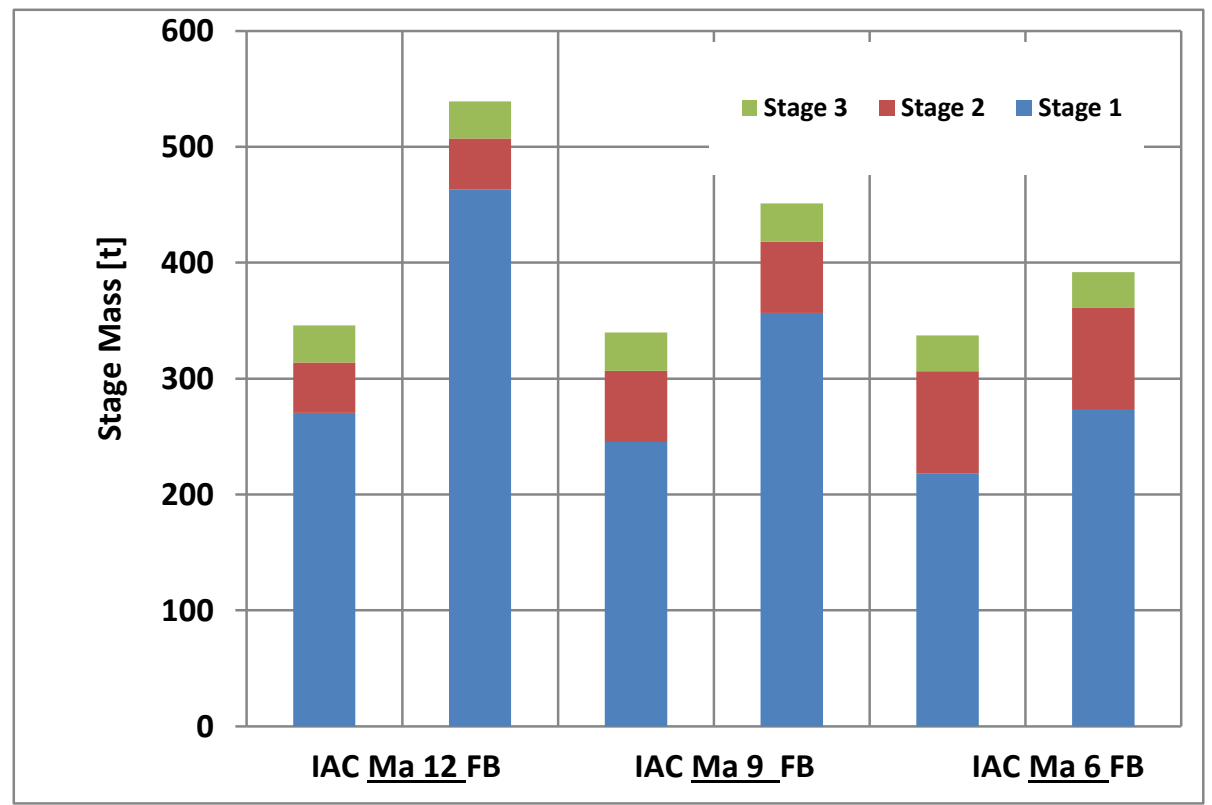

Figure 18: Stage Lift-Off Masses

This study presents first preliminary design computations that are conducted in DLR to assess different return options for reusable first stages. The advantage of in-air capturing over fly-back for high separation Mach numbers is shown. It is planned to include further return options and continue the comparison of different return options at a greater level of detail in the future.

\section{Acknowledgements}

The authors gratefully acknowledge the support of Dr. Josef Klevanski and Etienne Dumont. 


\section{References}

1. Sippel, M., Manfletti, C., Burkhardt, H.: Long-term strategic scenario for reusable booster stages, Acta Astronautica 58 (2006) 209-221

2. Burkhardt, H., Sippel, M., Klevanski, J.: ASSC-2 (Liquid Fly Back Booster with Ariane 5) System Requirements, Issue: 1 Revision: 1, ASTRA Doc. No. 1000-013, SART TN007/2004, DLR-IB 647-2004/05, 7 December 2004

3. Patentschrift DE $10147144 \mathrm{C} 1$, Verfahren zum Bergen einer Stufe eines mehrstufigen Raumtransportsystems, 2003.

4. Sippel, M., Klevanski, J.: Progresses in Simulating the Advanced In-Air-Capturing Method, 5th International Conference on Launcher Technology, Missions, Control and Avionics, S15.2, Madrid, November 2003

5. Bauer, C., David, E., Dumont, E., Garbers, N., Herbertz, A., Johannsson, M., Koch, A., Ludwig, C., Manfletti, C.: META CE Workshop, Technical Note, XTRAS-TN-METACE-20140303, pp. 16 - 18, 2014

6. Sippel, M., Schwanekamp, T.: Staged Combustion Cycle Rocket Engine Subsystem Definition for Future Advanced Passenger Transport, Space Propulsion 2014

7. Klevanski, J., Sippel, M.: Quasi-Optimal Control for the Reentry and Return Flight of an RLV, $5^{\text {th }}$ International Conference on Launcher Technology, Madrid 2003

8. Sippel, M., Klevanski, J., Kauffmann, J.: Innovative Method for Return to the Launch Site of Reusable Winged Stages, IAF-01-V.3.08, 2001

9. Sippel, M., Klevanski, J.: Simulation of Dynamic Control Environments of the In-AirCapturing Mechanism, $6^{\text {th }}$ International Symposium on Launcher Technology 2005, B1.4

10. Antonenko, S., Belavskiy, S.: The Mid-Air Retrieval Technology for Returning of the Reusable LV's Booster, $2^{\text {nd }}$ EUCASS, 1.03.08, July 1 - 6, 2007

11. http://spaceflightnow.com/2015/04/14/ula-chief-explains-reusability-and-innovation-of-newrocket/ 